\title{
PHYSIOLOGICAL STUDY ON NANO PARTICLES TO IMPROVE IMMUNE RESPONSE AND PERFORMANCE OF BROILER CHICKEN.
}

\author{
Ghada G. Gad ${ }^{1}$ and E.A. Abdalla ${ }^{2}$ \\ ${ }^{1}$ Poultry Production Department, Faculty of Agriculture, Ain Shams University, Cairo, Egypt. \\ 2.Poultry. Breeding. Department, Animal Production Research. Institute, Agricultural Center Dokki, \\ Giza. Egypt
}

(Received 8/10/2019, accepted 26/11/2019)

\section{SUMMARY}

A total of 600 fertile broiler breeder eggs were divided randomly into 6 treatments with four replicates. On the $7^{\text {th }}$ day of incubation, $0.1 \mathrm{ml}$ solution was in ovo injected into the air cell. The first group served as control without any injection, while the $2^{\text {nd }}$ group was injected with $0.1 \mathrm{ml}$ saline solution, the $3^{\text {th }}$ group was injected with $0.1 \mathrm{ml}$ nano organic iron, the $4^{\text {th }}$ group was injected with $0.1 \mathrm{ml}$ nano inorganic iron, the $5^{\text {th }}$ group was injected with $0.1 \mathrm{ml}$ inorganic iron and the $6^{\text {th }}$ group was injected with $0.1 \mathrm{ml}$ organic iron. The injected dose of each iron solution is $0.1 \mathrm{ml} / \mathrm{egg}$ containing $75 \mathrm{ppb}$ of different iron sources (nano, inorganic and organic). After incubation, chicks were reared up to $6 \mathrm{wks}$ of age and productive performance and immune response parameters were measured. Results indicated that, supplemental iron have increased the levels of immunoglobulins( IgG and IgM) and relative weights of spleen, bursa and thymus, and stimulated some histological change in the immune related organs which may result in improvement of chick immunity .A

Keywords:In ovo Iron nanoparticles, blood constitutes, histology, immune organs, broiler.

\section{INTRODUCTION}

Minerals are vital for maintaining homeostatic conditions in living organisms and their shortage can impact significantly the health and wellbeing of animals. Iron is essential for animal and poultry so it supplemented in their diets. Iron is an integral part of many proteins and enzymes that maintain good health. Majority of iron is present in the erythrocytes as hemoglobin (molecule that contains one hem group and one protein chain in each of its four units) Conrad et al., (1999). It is also essential for the regulation of cell growth and differentiation, the production of hemoglobin, myoglobin and the component of red blood cells that transports oxygen around the body. Iron (Fe) act as a cofactor for the function of over 300 different enzymes (Romanoff, 1967; Lozoff et al., 2006) and is an important structural cofactor for many proteins, including DNA synthesis and oxygen transport (Whitnall and Richardson, 2006; Scott and Chen ,2008; Li and Zhao, 2009). Iron is involved at every stage of the tricarboxylic acid cycle, and iron-containing catalase and peroxidases remove potentially dangerous products of metabolism, while iron-activated hydroxylases influence the connective tissue development Suttle 2010. Normal embryonic growth and development depends on a complete supply of all required nutrients within the egg. NRC 1994 recommended 50-120 ppm of iron for poultry and 2,000 ppm for tolerance limit.

Currently, nanoparticle are inorganic or organic particles with diameters ranging from 1 to $100 \mathrm{~nm}$, while there are examples of nanoparticles (NPs) which

are several hundreds of nanometers in size. (Nel et al., 2006). Nano particles have features, such as large surface area (increasing physical, chemical, and biological activities) and higher solubility and mobility (Diman et al., 2018 and Toyooka, et al., 2009). High surface to volume ratio allows the functionalizing of nanoparticles with different ligands, coatings and other useful tools for lots of biomedical applications.

Nano particles have many novel properties compared with the bulk materials. There are several areas in which nanotechnology could be applied to the science and engineering of agriculture, animal and food systems Oberdorster etal 2007. Metal nanoparticles are less toxic than salts of the same metals and have 


\section{Gad and Abdalla}

an advantage of a prolonged effect on biological objects Kovalenko and Folmanis 2006. Toxicological studies of nano sized iron have shown that such iron powders are low toxic. Iron oxide nanoparticles are inherently biocompatible due to their general stability in air and their ability to be degraded or metabolized in vivo, making them excellent candidates for a large variety of applications (Saki et al., 2014).

Demortiere et al., (2011) concluded that Fe In ovo feeding is beneficial for enhancing the immune response. Fe was found modulating the expression of humoral or cellular immunity related genes. Zhai et al., (2015) indicated that in ovo injected into the egg yolk sac with 25- 125 ppm Iron nanoparticles improved embryonic growth and body weight.

The immune system of the bird is partly developed at hatch. Trace minerals are important nutritional components for imparting immunity and in ovo enrichment can be a way for improving the immune system of the birds. Akshat et al., (2012) reported that the trace minerals are important nutritional components for imparting immunity and in ovo injected of iron during incubation into the yolk sac/amnion of the broiler embryos can be a way for improving the immune system of the birds. Iron nanoparticles and Alimet chelate form, as the active ingredient of feed additives, premixes, and compound feed, due to the high surface activity and penetration into cells can actively influence the intracellular metabolism by stimulating various processes.

Therefore, the objective of this study was carried out to determine the effect of in ovo injection of broiler eggs with different forms of iron on immunological, blood parameters, and lymphoid organs histology of broiler chicks.

\section{MATERIALS AND METHODS}

A total of 600 eggs from a Arbor Acres broiler breeder flock (42 weeks of age) were used in the present study. Eggs were divided randomly into 6 treatments with four replicates each. All eggs were incubated at $37.6 \mathrm{C}$ and relative humidity of 55 to $60 \%$ during the first 18 days of incubation then at 36.2 $\mathrm{C}$ and $65-70 \%$ relative humidty in the setter until hatching.

The first group served as control eggs were normally incubated without any injection, while the $2^{\text {nd }}$ group was in ovo injected with $0.1 \mathrm{ml}$ saline solution, the $3^{\text {th }}$ group was injected with $0.1 \mathrm{ml}$ nano organic iron, the $4^{\text {th }}$ group was injected with $0.1 \mathrm{ml}$ nano inorganic iron, the $5^{\text {th }}$ group was injected with $0.1 \mathrm{ml}$ inorganic iron and the $6^{\text {th }}$ group was injected with $0.1 \mathrm{ml}$ organic iron .

Iron oxide nanoparticles were prepared according to Reimers and Khalafalla (1974), suspended in Kno DMEM cell culture medium and dispersed by an ultrasonic bath. The injected dose of each iron solution is $0.1 \mathrm{ml} / \mathrm{egg}$ containing $75 \mathrm{ppb}$ of different iron sources (nano, inorganic and organic).

Post-hatch, a total number of 480 one-day old chicks were distributed in to six equal treatment groups with four replicates each according the corresponding treatments. Experimental chicks were kept under similar environmental conditions. Chicks were fed on a commercial starter and grower basal rations until six weeks of age. Both diets were formulated to meet NRC ( 1994 ) requirements.

Plasma total protein $(\mathrm{g} / \mathrm{dl})$ was determined according to the method described by Henry (1964), the determination of plasma albumin was carried out according to the method of Doumas et al. (1971), globulin was calculated by subtraction of plasma albumin from total plasma protein. Plasma samples from each treatment were tested for total antibodies response directed specifically against the triggering NVD. White cells were counted and differentiated into lymphocytes $(\mathrm{L})$, heterophils $(\mathrm{H})$ and other types, and the ratio of $\mathrm{H}$ to $\mathrm{L}$ was calculated. Immunoglobulin concentrations $\operatorname{IgG}$ and $\operatorname{IgM}$ were determined by enzyme-linked Immunosorbent assays using commercial ELISA kits according to manufacturer's Instructions (Sun Biomedical Technology Co., BeiJing, 10039) Bianchi et al. (1995).

Histological examination: At the end of the experiment, representative tissue samples from Bursa , thymus and spleen gland were taken at slaughtering time to study the histological changes associated with the experimental treatments. Samples were fixed in a $10 \%$ formalin-saline solution before preparing the histological slices by using Paraffin histological technique where, specimens were dehydrated in ascending grades of ethanol, cleared in Zylene and then embedded in paraffin wax. Transverse sections (4-5microns, thickness) were cut, mounted on glass slides and then stained with haemotoxyline and eosin (H\&E) stains according to methods described by (Ker et al., 1982). All sections were examined by using an electric light microscope provided with computerized Camera. 


\section{Statistical analysis :}

The obtained data on immunological parameters, and blood parameters were analyzed using statistical analysis system (SAS, 1996). In order to determine significant differences between all possible mean comparisons Duncan`s multiple range test Duncan (1955) was applied. Statistical significance was accepted at a probability level of 0.05 .

\section{RESULTS AND DISCUSSION}

\section{Relative weight of lymphoid organs}

Results in Table 1 showed that the relative weight of bursa, thymus and spleen were significantly $(p<0.05)$ improved by the different forms of Iron in either nano particle or in the organic or inorganic forms injected groups than un-injected control group. These results are agreement with those obtained by Goel et al (2013)who found that in ovo feeding of iron may influence the embryonic development, while iron can play an important role in post hatch growth also.

Table (1): Effect of in ovo injection of different iron and nano iron forms on relative weight of bursa ,thymus and spleen (\% of live body weight) of broiler chicks at six weeks of age.

\begin{tabular}{lllllllll}
\hline Treatment & $\mathrm{C}$ & $\mathrm{S}$ & $\mathrm{NO}$ & $\mathrm{Ni}$ & $\mathrm{In}$ & $\mathrm{O}$ & $\mathrm{MSE}$ & Sig \\
\hline Bursa $\%$ & $0.118^{\mathrm{c}}$ & $0.119^{\mathrm{c}}$ & $0.155^{\mathrm{a}}$ & $0.147^{\mathrm{a}}$ & $0.147^{\mathrm{a}}$ & $0.120^{\mathrm{b}}$ & 0.01 & $* *$ \\
thymus\% & $0.122^{\mathrm{b}}$ & $0.127^{\mathrm{b}}$ & $0.239^{\mathrm{a}}$ & $0.230^{\mathrm{a}}$ & $0.204^{\mathrm{a}}$ & $0.216^{\mathrm{a}}$ & 0.01 & $* *$ \\
Spleen\% & $0.101^{\mathrm{c}}$ & $0.096^{\mathrm{c}}$ & $0.155^{\mathrm{b}}$ & $0.169^{\mathrm{a}}$ & $0.143^{\mathrm{b}}$ & $0.162^{\mathrm{a}}$ & 0.01 & $*$
\end{tabular}

Means within a row with different superscripts are significantly different $(P \leq 0.05)$.

$C=$ Control, $S=$ Saline, ,NO = Nanoorganic, $N i=$ Nano Inorganic, In = Inorganic, $O=$ organic -

\section{White blood cells differential count (WBC's):}

The effect of in ovo injection of different iron forms on WBC's differential count of broiler chicks is presented in Table 2

Results showed that WBc's count was significantly increased in chick from organic iron injected group followed by those of saline and the control groups, respectively compared by the other treatments. This increase was also observed in the percentage of lymphocytes where their percentages were significantly higher in saline injected, nano- organic and inorganic and organic iron injected groups compared with the other treatments. This was not the case for the heterophils percentage, were the highest values were recorded for nano-inorganic, , inorganic and then the control groups, respectively. The lowest values observed for control group respectively. This change in the hetrophils and lymphocytes were reflected in there ratio $(\mathrm{H} / \mathrm{L})$ where it is significantly higher in the, nano -inorganic ,inorganic and the control groups respectively compared with the other treatments.

Although significantly differences in the most WBC's percentage all of them are in the normal range of blood hematological traits indicative of apparently blood homeostasis pattern Sturkie,(1986).

The higher H/L ratio may indicate a state of stress responses of birds to internal and/or external stressors that resulted in an increase in heterophils count as the main phagocytic cells in the body which in turn increased H/L ratio as the case in some treatment groups in our study. However, the groups had achieved better growth performance during the whole experiment indicative of a mild stress or normal acceptable stress.

It is assumed that the higher $\mathrm{H} / \mathrm{L}$ ratio of some treatment groups may be resulted from the increase of metabolic activity of the chicks accompanied with an increase in metabolic heat production representing a state of stress that caused an increase in $\mathrm{H} / \mathrm{L}$ ratio without any negative impacts on chicks' productivity. In this concern, Gross and Siegel (1983) reported that H/L ratio was considered as a more reliable indicator for determining stress response in poultry. 
Table (2): Effect of in ovo injection of different iron and nano iron forms on white blood cells differential count of broiler chicks at six weeks of age.

\begin{tabular}{lcccccccc}
\hline Treatment & $\mathrm{C}$ & $\mathrm{S}$ & $\mathrm{NO}$ & $\mathrm{Ni}$ & $\mathrm{In}$ & $\mathrm{O}$ & MSE & Sig \\
\hline WBC's $\left(10^{3} \mathrm{~mm}^{3}\right)$ & $12.12^{\mathrm{ab}}$ & $14.23^{\mathrm{a}}$ & $11.33^{\mathrm{b}}$ & $10.87^{\mathrm{b}}$ & $11.82^{\mathrm{ab}}$ & $14.47^{\mathrm{a}}$ & 1.11 & $*$ \\
Lymphocytes \% & $56.7^{\mathrm{ab}}$ & $61.3^{\mathrm{a}}$ & $59.7^{\mathrm{a}}$ & $60.4^{\mathrm{a}}$ & $53.7^{\mathrm{b}}$ & $60.3^{\mathrm{a}}$ & 4.31 & $*$ \\
Heterophils \% & $35.3^{\mathrm{a}}$ & $29.7^{\mathrm{b}}$ & $30.3^{\mathrm{b}}$ & $38.6^{\mathrm{a}}$ & $36.7^{\mathrm{a}}$ & $31.7^{\mathrm{b}}$ & 2.42 & $*$ \\
Monocytes \% & 5.12 & 5.31 & 618 & 5.14 & 6.32 & 5.20 & 0.46 & $\mathrm{NS}$ \\
Eosinophils \% & 3.14 & 3.67 & 4.13 & 3.33 & 3.67 & 3.33 & 0.32 & NS \\
H/Lratio & $0.62^{\mathrm{a}}$ & $0.48^{\mathrm{b}}$ & $0.51^{\mathrm{b}}$ & $0.64^{\mathrm{a}}$ & $0.68^{\mathrm{a}}$ & $0.53^{\mathrm{b}}$ & 0.04 & $*$ \\
\hline
\end{tabular}

Means within a row with different superscripts are significantly different $(\mathrm{P} \leq 0.05)$

$\mathrm{C}=$ Control, $\mathrm{S}=$ Saline,, $\mathrm{NO}=$ Nanoorganic, $\mathrm{Ni}=$ Nano Inorganic, $\mathrm{In}=$ Inorganic, $\mathrm{O}=$ organic.

\section{Plasma protein concentration:}

Results in Table (3) showed the effect of different iron and nano iron sources on plasma protein fractions of broiler chick at six weeks of age

It is clear from the results obtained that plasma total protein was significantly increased in all the control groups compared to the different forms of Iron in nano particle or in the organic or inorganic forms injected groups. This was reflected in the $\mathrm{A} / \mathrm{G}$ ratio which was significantly higher in these groups.

The previous result indicates that in ovo injection itself has no harmful effect on different plasma protein parameters, this means that iron injection has a positive impact on protein synthesis. It suggested that plasma proteins profile of a given bird is a reflection of the metabolic activities related to protein synthesis and /or degradation, this support the findings of many authors who observed that iron has the ability to bind protein and enhanced DNA synthesis which in turn affect plasma protein level at different growth periods Angle ,(2007); and Yair and Uni,(2011).

Table (3): Effect of in ovo injection of different iron forms and nano iron on plasma proteins, of six week of age broiler chicks.

\begin{tabular}{lllllllll}
\hline Treatment & $\mathrm{C}$ & $\mathrm{S}$ & $\mathrm{NO}$ & $\mathrm{Ni}$ & $\mathrm{In}$ & $\mathrm{O}$ & $\mathrm{MSE}$ & Sig \\
\hline $\begin{array}{l}\text { Total protein } \\
(\mathrm{g} / \mathrm{dl})\end{array}$ & $5.66^{\mathrm{a}}$ & $6.13^{\mathrm{a}}$ & $5.04^{\mathrm{b}}$ & $5.28^{\mathrm{b}}$ & $4.89^{\mathrm{c}}$ & $3.89^{\mathrm{c}}$ & 0.34 & $*$ \\
$\begin{array}{l}\text { Albumin } \\
\text { (g/dl) }\end{array}$ & 2.69 & 2.86 & 2.80 & 2.53 & 2.97 & 2.12 & 0.04 & $\mathrm{NS}$ \\
$\begin{array}{l}\text { Globulin } \\
(\mathrm{g} / \mathrm{dl})\end{array}$ & $2.97^{\mathrm{a}}$ & $3.27^{\mathrm{a}}$ & $2.24^{\mathrm{b}}$ & $2.75^{\mathrm{a}}$ & $1.92^{\mathrm{b}}$ & $1.77^{\mathrm{b}}$ & 0.33 & $* *$ \\
A/G ratio & $0.905^{\mathrm{b}}$ & $0.874^{\mathrm{b}}$ & $1.25^{\mathrm{a}}$ & $0.92^{\mathrm{b}}$ & $1.54^{\mathrm{a}}$ & $1.19^{\mathrm{a}}$ & 0.08 & $*$ \\
\hline
\end{tabular}

Means within a row with different superscripts are significantly different $(P \leq 0.05)$.

$C=$ Control, $S=$ Saline,,$N O=$ Nanoorganic, $N i=$ Nano Inorganic, $I n=$ Inorganic, $O=$ organic .

Immunoglobulin concentration and antibody titer:

Results in Table 4 summarized the effect of different iron forms, when in ovo injection, on immune responses of broiler chicks at six weeks of age.It could be observed that the levels of immunoglobulin's (IgG and $\operatorname{IgM})$ were significantly higher $(\mathrm{P}<0.05)$ in iron-supplemented groups than the controls however, the highest values $(\mathrm{p}<0.05)$ of immunoglobulin's were observed in Nano iron group. These results are agreement with Cai et al., (2012) who found a significant effect of nano-Fe in IgG and IgM, however, no significant difference on serum IgA concentration. In this respect, Warnar et al., (2006) showed that the highest liver weight increased biochemical constituents, enhanced generation of total IgG as well as exhibiting pleiotropic effects in inflammatory responses. They added that in serum was observed in treatments .Moreover; on the other hand, antibody titer against NDV was significantly higher for all chicks from iron injected groups than the control ones, indicative of better immunity. It should be mentioned that antibody titer was measured randomly after the normal vaccination program.

These results are in close agreement with those reported by Malik et al., (2011) who injected in ovo $80 \mathrm{ug}$ of iron at the 14th day of incubation; Lin, et al (2012) and seo, et al (2008) who used graded level of Fe- nano ,they reported an improvement in humeral immune responses of broiler chicks. 
Table (4): Effect of in ovo injection of different iron and nano iron forms plasma immunoglobulin concentrations of broiler chicks at six weeks of age.

\begin{tabular}{lllllllll}
\hline Treatment & C & S & NO & Ni & In & O & MSE & Sig \\
\hline IgG (ug/ml) & $624.9^{\mathrm{b}}$ & $611.1^{\mathrm{b}}$ & $692.0^{\mathrm{a}}$ & $671.9^{\mathrm{a}}$ & $635.7^{\mathrm{b}}$ & $642.0^{\mathrm{b}}$ & 18.38 & $*$ \\
IgM (ug/ml) & $118.3^{\mathrm{b}}$ & $120.7^{\mathrm{b}}$ & $152.5^{\mathrm{a}}$ & $148.0^{\mathrm{a}}$ & $132.5^{\mathrm{ab}}$ & $120.4^{\mathrm{b}}$ & 7.25 & $*$ \\
IgA (ug/ml) & 153.0 & 134.1 & 152.9 & 153.9 & 143.8 & 131.3 & 7.42 & NS \\
Ab-Titer & $5.30^{\mathrm{c}}$ & $5.92^{\mathrm{c}}$ & $7.12^{\mathrm{a}}$ & $6.74^{\mathrm{a}}$ & $6.43^{\mathrm{b}}$ & $5.92^{\mathrm{c}}$ & 0.33 & $*$ \\
\hline
\end{tabular}

Means within a row with different superscripts are significantly different $(P \leq 0.05)$.

$C=$ Control, $S=$ Saline, , $N O=$ Nanoorganic, $N i=$ Nano Inorganic, $I n=$ Inorganic, $O=$ organic

\section{Histological observations:}

\section{1- Bursa of Fabricius:}

The histological examination of bursa sections from different treatments indicated that the basic histological structure of the bursal tissues is nearly similar in all treatments (Fig.1-6).

In general, the bursa of Fabricius is a primary lymphoid organ in birds . It is composed of about 15 20 plicae (folds) each of them contain numerous follicles (f) with various sizes (tall or short). These follicles have two distinct areas, i.e. cortex (C) and medulla (M) inclosed in a pseudostratified columnar epithelial outer layer (e) as shown in all sections, especially Fig. 3, 4, 5 and 6. They were separated from each other by fine connective tissue septa $(\mathrm{S})$, while their secretions are collected in lumens (L).

Section clearly showed that the cortex is more deeply stained than the medulla due to the fact that it composed of many small lymphocytes, whereas the medulla appeared as a pale-stained area containing large lymphocytes, undifferentiated epithelial cells (d) and lymphoblasts. This structure was clearly observed in bursa section from both Nano iron treatments (Fig. 3, 4) followed by those from organic and inorganic treatments (Fig. 5; 6). The effect of in ovo injection of different iron sources and forms during incubation period revealed a positive impact on bursa histology in terms of increased the number of follicles / microscopic field, along with a narrow connective tissue septa (S) between follicles compared by chicks from the control and treatments. This was not the case for the bursa section from birds that hatched from the control and saline- injected treatments, where the bursal follicles were pale - stained with nearly similar small sizes.

It is of interest to observe that the improved histological appearance of bursal follicles in response to in ovo iron treatments, especially as shown in Fig 3, 4, 5 and 6 was associated by an obvious increase in the cortex area with apparently better and well -developed epithelium covering (e) of the whole plicae area .

It is likely that under the prevalent conditions of the present study, in which post hatched chicks were reared under similar environmental conditions, there was a marked reduction in the cortical area of bursa follicles indicative of negative effect on immune responses of birds in these groups (Fig.1 and 2). Additionally, in ovo injection of different iron forms exerts beneficial effects on bursal function via its effect on promoting immunoglobulins secretion as the number of lymphocytes increased. Our results are in close agreement with the findings by Ciriaca, et al.(2003); Akter,et al.(2006); and Sławińska et al.(2014) who reported a strong correlation between the relative size of bursa, its histological structure and the average level of $\mathrm{IgG}$ production, so the maintenance of functional B-lymphocytes .

\section{Thymus histology:}

The histological structure of thymus gland as affected by different treatments is illustrated in Fig. 7 to 12.In general, the gland is enclosed by a thin connective tissue capsule of coarse collagen fibers and few elastic fibrils. There are many fine septa (s) that divide the gland to several thymic lobules (L) differing in their size and shape. In addition each thymic lobule is composed of outer- dark- stained areas cortex (c) area and a pale region located in the lobules center or merged in the cortex area ( medulla, M ). It is clearly observed that the cortex area contains many small and large lymphocytes (Ly) especially in the section of chicks from the nano iron - treated groups of chickens (Fig. 9 to Fig.12). While, section from control chicks (Fig. 7 ; 8) showed little response to the applied treatments in terms of their thymus histological architecture. This may be resulted from the fact those chicks had better bursa histological appearance which may support the well known findings that the immune response of chicks at older ages depends mainly on B - lymphocyts production (Bursal - origin), than T-lymphocytes from thymus glands. This was confirmed by the results obtained by Akter et al.(2006) and more recently by khan et al.(2014) who discussed the developmental changes of lymphoid organs in chickens . 


\section{Gad and Abdalla}

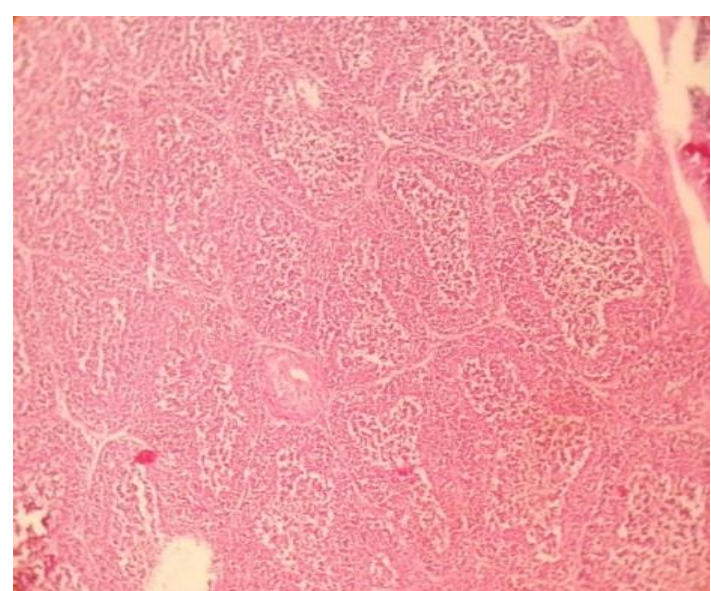

Fig. 1. T.S. through bursa of Fabricius from chicks of the control treatment (H\&E x 100)

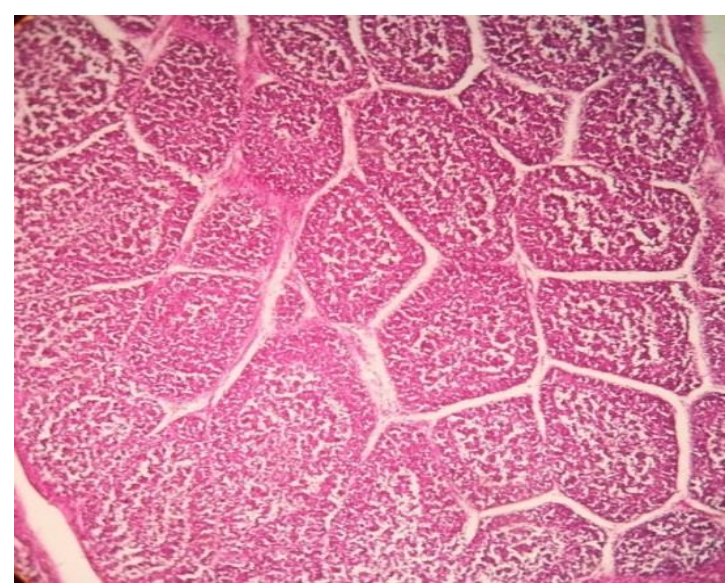

Fig. 3. T.S. through bursa of Fabricius from chicks of the NO- treatment ( $\mathrm{H} \& \mathrm{E} \times 10)$

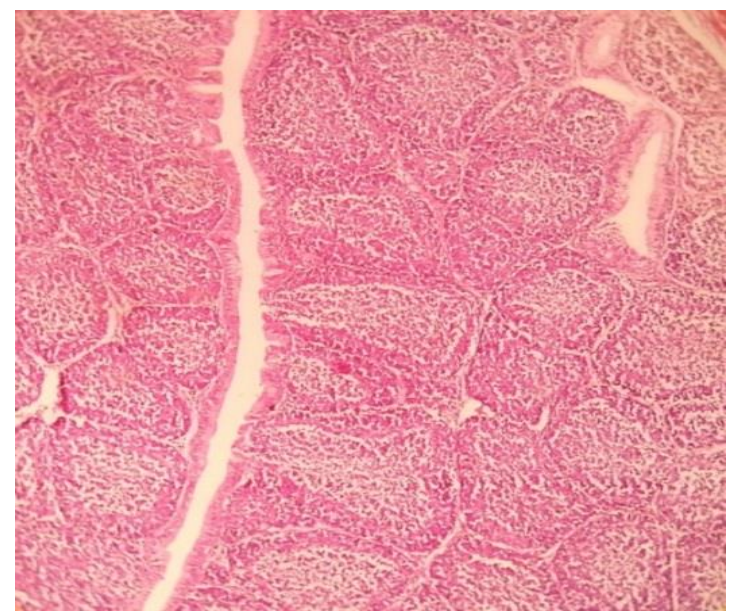

Fig. (5). T.S. through bursa of Fabricius from of the Ino - treatment (H\&E x 100).

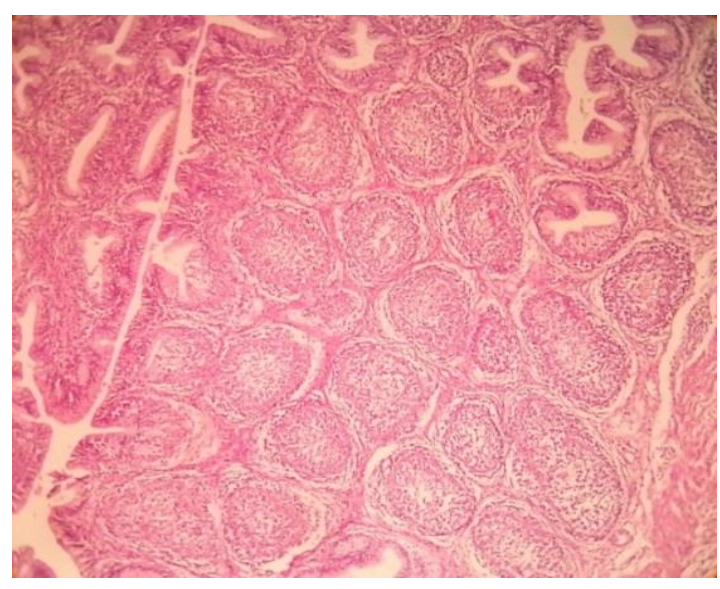

Fig. 2. T.S. through bursa of Fabricius

from chicks of the Saline- treatment (H\&E x100)

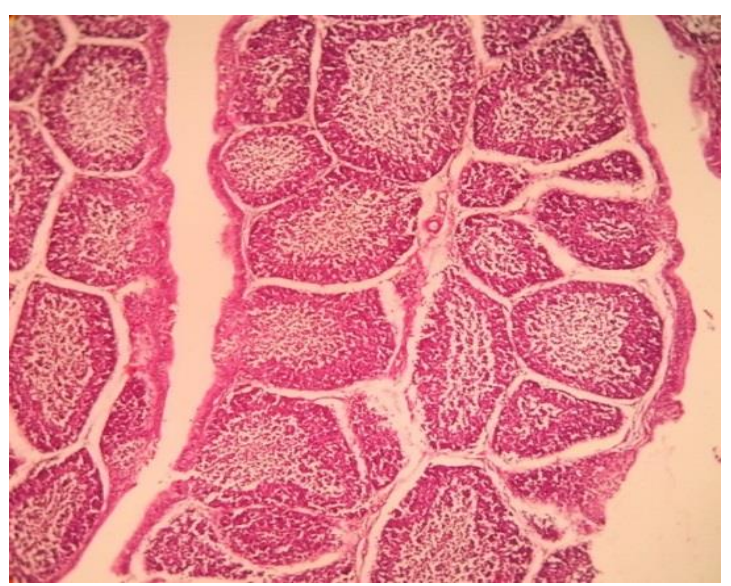

Fig. 4. T.S. through bursa of Fabricius from chicks of the Nio - treatment (H\&E x 100)

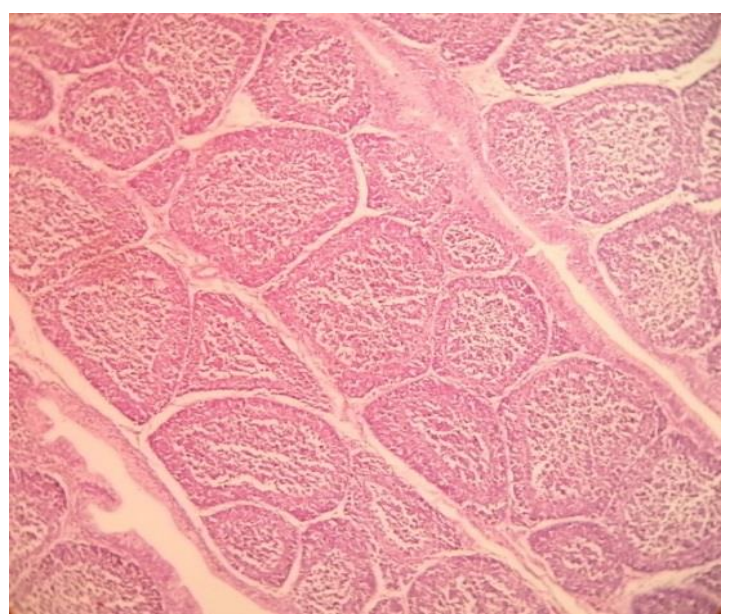

Fig. (6): T.S. through bursa of Fabricius from chicks of the $\mathrm{O}$ - treatment (H\&E x 100).

Abbreviation key for bursa sections:

$\mathrm{C}=$ cortex, $\mathrm{E}=$ Pseudostratified columnar epithelium, $\mathrm{F}=$ Bursa follicles, $\mathrm{M}=$ Medulla, $\mathrm{T}=$ Connective tissue septa 
So, it is likely that the effect of in ovo injection of different iron forms during embryogenesis, caused less prominent histological changes in thymus gland, unlike the bursa of Fabricius. In this concern, our results, however, showed an obvious improvement in the histological appearance of thymus gland in response to to different Fe sources and levels.

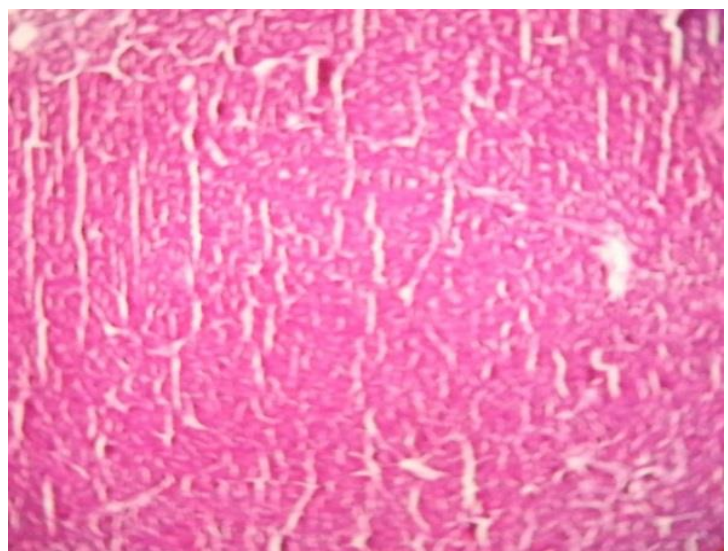

Fig. (7). T.S. through thymus from chicks of the control treatment (H\&E x 100)

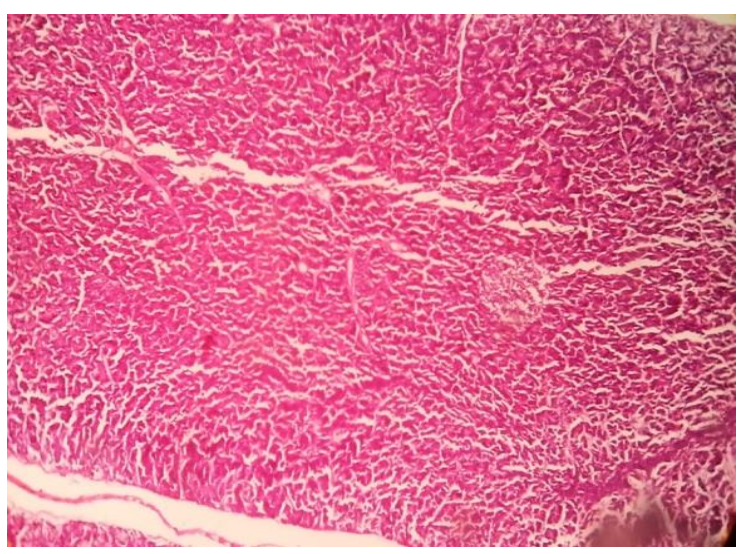

Fig. 9: T.S. through thymus from chicks of the NOtreatment (H\&E x 10).

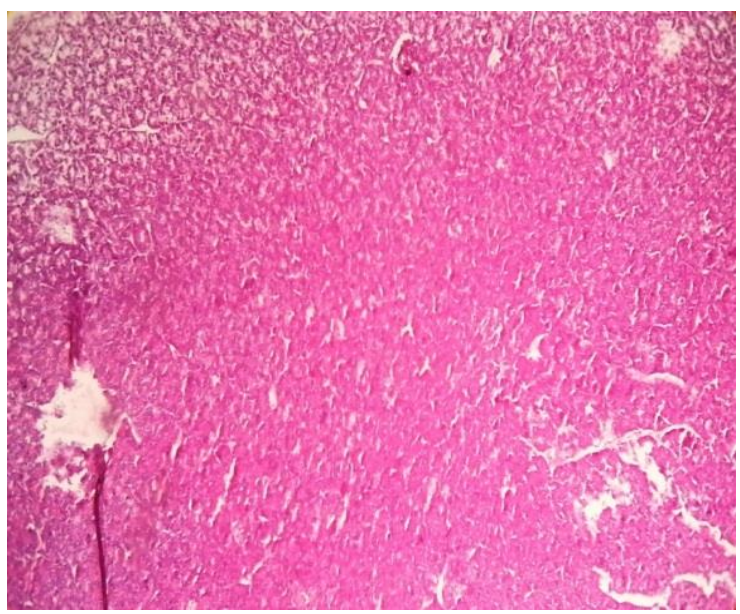

Fig. 11: T.S. through thymus from chicks of the In treatment (H\&E x 10)

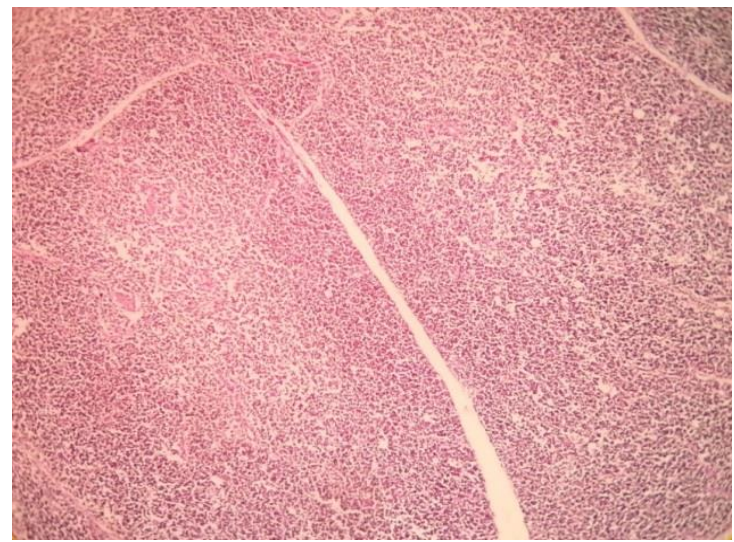

Fig. 8. T.S. through thymus from chicks of the Saline- treatment (H\&E x100).

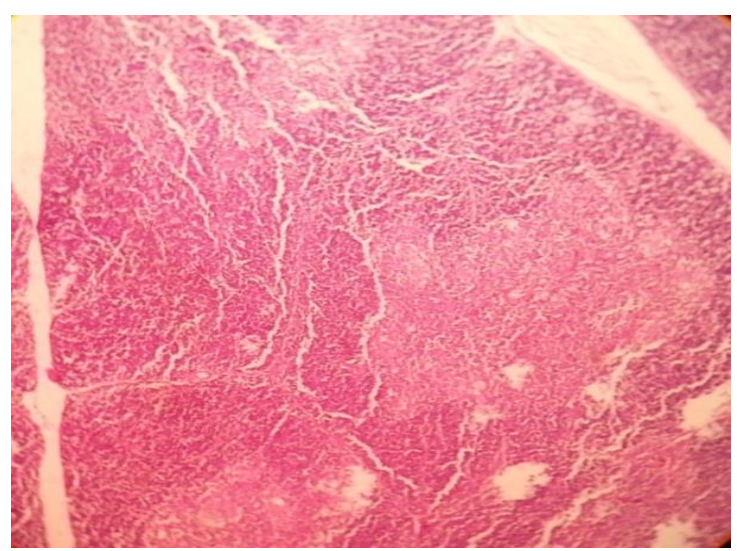

Fig. 10: T.S. through thymus from chicks of the $\mathrm{Ni}$ - treatment (H\&E x 10).

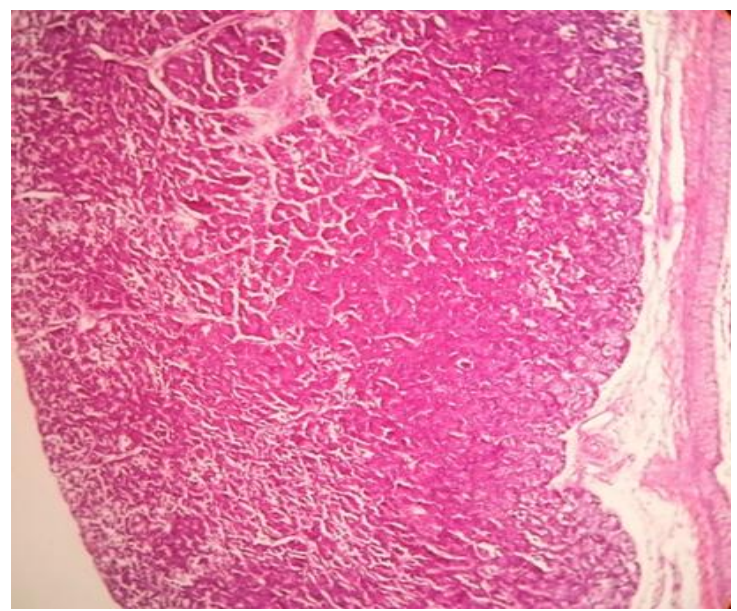

Fig. 12: T.S. through thymus from chicks of the $\mathrm{O}$ - treatment (H\&E x 10).

Abbreviation Key for Thymus gland:

$\mathrm{C}=$ Cortex, $\mathrm{M}=$ medulla, $\mathrm{V}=$ blood Vessel, $\mathrm{L}=$ thymic lobule, $\mathrm{S}=$ Connective tissue Septa, $\mathrm{Ly}=$ lymphocytes 


\section{Gad and Abdalla}

\section{Spleen histology:}

The histological structure of the spleen as influenced by different in ovo iron injection treatments is illustrated in Fig. 13 to 17. It is clear from these sections that the basic architecture of spleen from different treatments has nearly similar structure, in which two main regions could be seen, i.e. a large white pulp area (WP) and a dark - stained red pulp area (RP) with numerous blood capillaries, sinusoids (S) and many lymphocytic cells of different sizes and numbers along with more or less lymphatic nodules.This was observed in the spleen section from the control groups (Fig.13;14). The same pattern was also observed in the spleen sections from nano-iron treatments (Fig.15; 16) but an increase in the RP area could be seen. Moreover, there were an irregular distribution of the RP area within the WP one, especially in the sections from chicks of the inorganic (Fig.17) and organic iron (Fig.18) treatments. Since, the RP area is extended all over the spleen sections with a marked increase in the number of large lymphocytes accompanied by basophilic hemosiderin granules in between the blood sinusoids. These large-sized lymphocytes may reflect an improvement in immune response of chicks from these treatment groups.

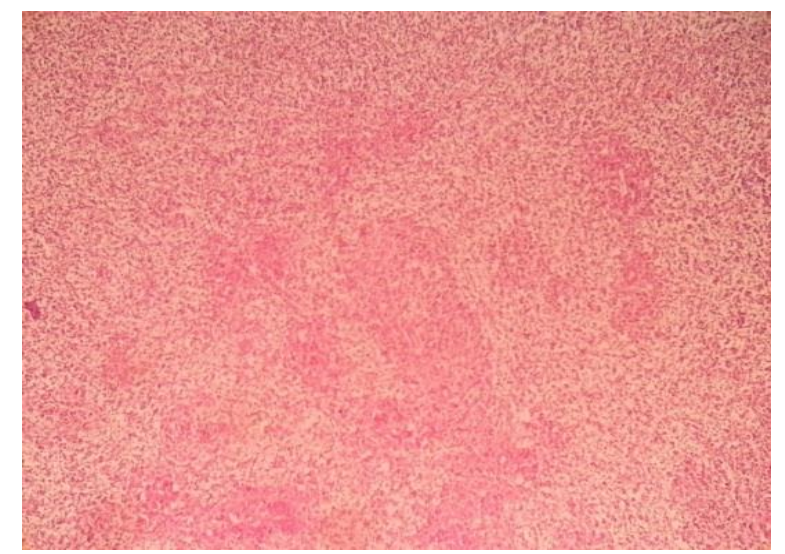

Fig. 13: T.S. through spleen from chicks of the control treatment (H\&E x 10)

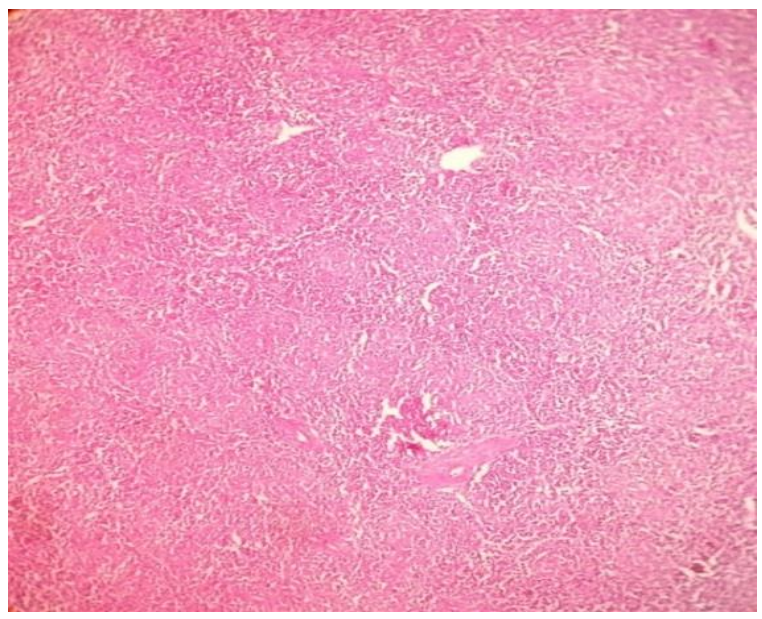

Fig. 15: T.S. through spleen from chicks of the No treatment (H\&E x 10)

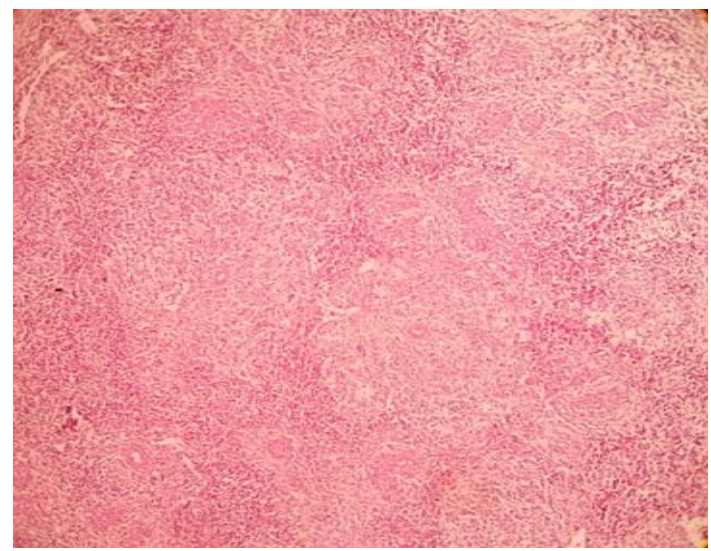

Fig. 14: T.S. through spleen from chicks of the $\mathrm{S}$ - treatment (H\&E x 10).

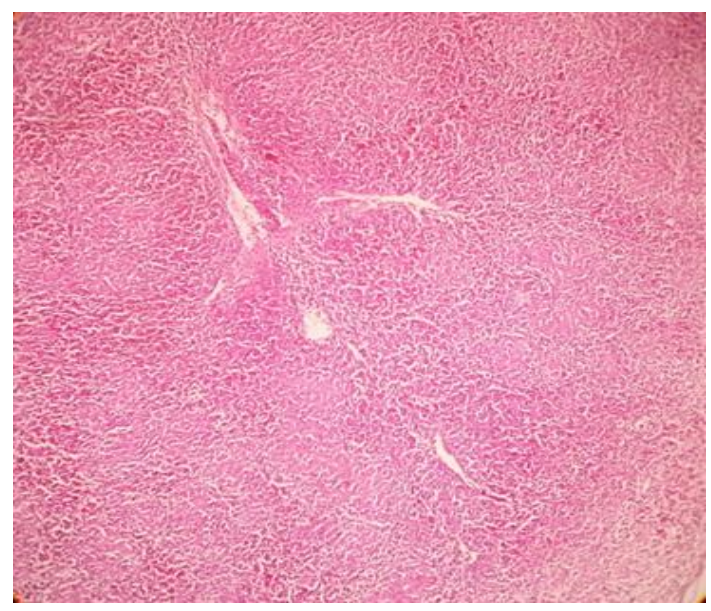

Fig. 16: T.S. through spleen from chicks of the $\mathrm{Ni}$ - treatment (H\&E x 10). 


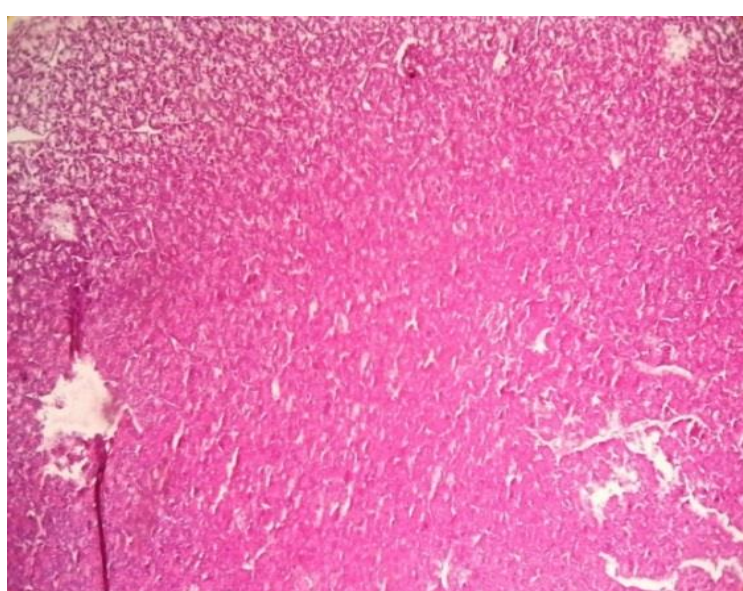

Fig. 17: T.S. through spleenfrom chicks of the In treatment (H\&E x 10)

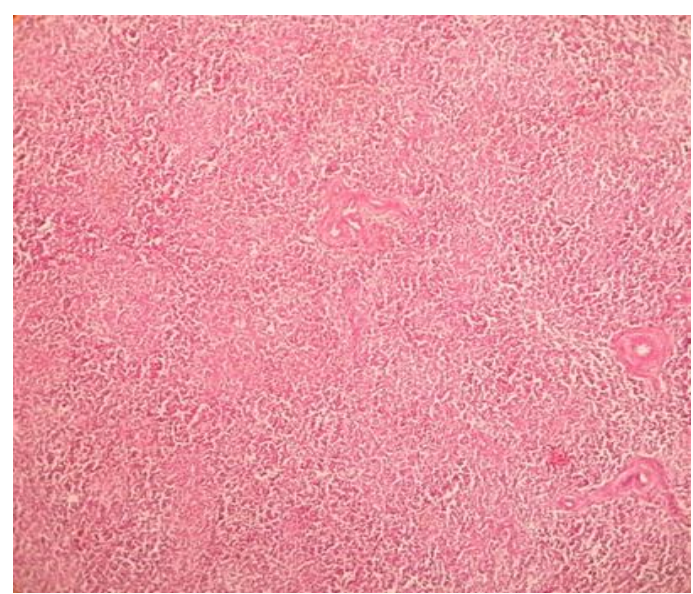

Fig. 11: T.S. through spleen from chicks of the O- treatment (H\&E x 10).

Abbreviation Key for spleen sections:

$\mathrm{b}=$ blood sinuses, $\mathrm{n}=$ lymphatic nodule, $\mathrm{Ly}=$ lymphocytes, $\mathrm{RP}=$ red pulp area, $\mathrm{WP}=$ white pulp area

In this respect, spleen in considered as a secondary lymphoid organ in birds, and it was reported by many authors to be the main site of lymphocytes proliferation and differentiation Hodges, 1974 and Slawińska, et al.(2014). The impact of in ovo iron treatments in enhancing the histological structure of spleen in our study is evidenced by the presence of many lymph nodules (n) which resembles the lymph nodes in mammals . These lymphatic nodules (follicles) have been reported to be directly related to better immunity of birds. Thus, there is evidence that the spleen of birds harbour large numbers of T-cells and B-cells which differentiate into antigen - specific effector cells. This concept was confirmed by the previous results by John (1994), Powers (2000); Sato, et al. (2004) and Slawińska et al. (2014). It is assumed that the spleen, as a secondary immune organ, has lesser sensitivity to the effect of iron injection into eggs during incubation than the primary immune organs (bursa and thymus). This assumption emphasized the results of Compton et al.(1990) who showed that organs where lymphocytes are stored, being less sensitive to the effect of different stressors . Also, Ardia (2005) stated that larger spleens provide stronger immunity as measured by PHA responsiveness test.

\section{CONCLUSION}

These results suggest that the in-ovo injection of 75-ppb iron nanoparticles As injection contributed to embryonic growth development and improved immunity .

\section{REFERENCES}

Akshat .G, S. K. Bhanja, Manish. M and Veena. P (2012). In ovo supplementation of selenium or iron enhanced the expression of immune related genes in broiler chickens. Indian Journal of Poultry Science. 39, 105-111

Akter, S.; M. Z. I. Khan; M. R. Jahan; M. R. Karim and M. R. Islam (2006). Histomorphological study of the lymphoid tissues of broiler chickens. Bangladesh Journal of Veterinary Medicine. 4(2): 87-92.

Angel R. (2007). Metabolic Disorders: Limitations to Growth of and Mineral Deposition into the Broiler Skeleton after Hatch and Potential Implications for Leg Problems J. Appl. Poult. Res. 16, 138-149.

Ardia, D. R. (2005). Cross-fostering reveals an effect of spleen size and nest temperatures on immune responses in nestling European starlings. Oecologia., 145(2): 326-333. 


\section{Gad and Abdalla}

Bianchi, A. T. J.; Moonen-Leusen, H. W. M.; van der Heijden, P. J. and Bokhout, B. A. 1995. The use of a double antibody sandwich ELISA and monoclonal antibodies for the assessment of porcine $\operatorname{IgM}$, IgG, and IgA concentrations. Vet. Immunol. Immunopathol. 44:309-317.

Cai M.-Q., Ling Z.-H., and Dai L.-R.(2012). Target-filtering model based articulatory movement prediction for articulatory control of HMM-based speech synthesis. In Signal Processing (ICSP), 2012 IEEE 11th International Conference on, volume 1, pages 605-608.

Ciriaco, E.; P.P. Píñera; B. Díaz-Esnal and R. Laurà (2003). Age-related changes in the avian primary lymphoid organs (thymus and bursa of Fabricius). Microscopy research and technique., 62(6): 482487.

Compton, M.M.; P.S. Gibbs and I.R. Johnson (1990). Glucocorticoid activation of deoxyribonucleic acid degradation in bursal lymphocytes. Poult. Sci., 69:1292-1298

Conrad, m. E., umbreit, j. N. \& moore, e. G. (1999). Iron Absorption and Transport. The American Journal of the Medical Sciences, 318, 213.

Demortiere, A.; Panissod, P.; Pichon, B. P.; Pourroy, G.; Guillon, D.; Donnio, B. and Begin-Colin, S. (2011). Size-dependent properties of magnetic iron oxide nanocrystals, Nanoscale, 3, 226.

Doumas B.T. (1971): Clin. Chim. Acta 31-87.

DimanRahmatollah, AmjadFarzinpour, AsaadVaziryand GhorbanaliSadeghi (2018)..Effect of

replacing dietary FeSO4 with cysteinecoated Fe3O4 nanoparticles on quails. Italian Journal of Animal Science. 2018 VOL. 17, NO. 1, 121-127

Duncan, D.B (1955). Multiple range and multiple F test. Biometrics, 11:1-42.

Goel, A.; Bhanja, S.K.; Mehra, M. ; Majumdar, S. and Pande, V. (2013). Effect of in ovo copper and iron feeding on post-hatch growth and differential expression of growth or immunity related genes in broiler chickens. Indian Journal of Poultry Science, 48(3): 279-285.

Gross W. B. and Siegel H. S. Siegel (1983). Evaluation of the Heterophil/Lymphocyte Ratio as a Measure of Stress in Chickens . Avian Diseases Vol. 27, No. 4 (Oct. - Dec., 1983), pp. 972-979.

Henry, R.J. (1964). Clinical Chemistry, Harber \& Row Publishers, New York. USA. 181.p.

Hodges, R. D. (1974). The histology of the fowl. Academic Press, Lodon, NY

John, J.I. (1994). The avian spleen: a neglected organ. Rev. Biol. 69:327-351

Ker, G.R.; Lae, E. S.; Ian, M. K. N.; Lomor, R. J. Randalb, E. and Forhoter, R. (1982). Relationships between dieting and biochemical measures of nutritional status. Ann. J. Chin. Nutr. 35: 294-308.

Khan M.; Ibrahim, A.A.M., Sohail, M., Qurashi, A., (2014). Discovery of novel oxindole derivatives as potent $\alpha$-glucosidase inhibitors. Bioorg Med Chem 22(13):3441-8

Kovalenko, L.V. and Folmanis, G.E., (2006).Biologicheski aktivnye nanoporoshki zheleza (Biologically Active Iron Nanoparticles), Moscow: Nauka,.

Li, M. and Zhao, C. (2009). Study on tibetan chicken embryonic adaptability to chronic hypoxia by revealing differential gene expression in heart tissue. Sci. China C. Life Sci., 52: 284-295.

Lin, s., q. Yin, q. Zhong, f. Lv, y. Zhou, j. Li, j. Wang, b. Su, q. Yang, (2012): Heme activates TLR4mediated inflammatory injury via MyD88/TRIF signaling pathway in intracerebral hemorrhage. Journal of Neuroinflammation , 9, 46-59.

Lozoff, b., n. Kacirot, t. Walter, (2006): Iron deficiency in infancy: Applying a physiologic framework for prediction. Am. J. Clin. Nutr. 84, 1412-1421.

Malik, i.a., n. Naz, n. Sheikh, s. Khan, f. Moriconi, m. Blaschke and, g. ramadori, (2011): Comparison of changes in gene expression of transferrin receptor-1 and other iron-regulatory proteins in rat liver and brain during acute-phase response. Cell Tissue Research. 344, 299-312.

Nel .A., T. Xia and L. Madler (2006): Toxic potential of materials at the nanolevel. Science.311(5761):622-627.

NRC. (1994). Nutrient Requirements of Poultry. National Academy Press, Washington, DC. USA. p. 27. 
Oberdorster, G.; Stone, V. and Donaldson, K. (2007). Toxicology of nanoparticles: A historical perspective. Nanotoxicology, 1(1): 2-25.

Powers, L.V., (2000). The avian spleen: anatomy, physiology; and diagnosis. Compendium on continuing education for the practicing veterinarian, 22:838-843.

Reimers G. W. and Khalafalla S. E. (1974). Production of Magnetic Fluids by Peptization Techniques. US Patent No. 3843540.

Romanoff, A., (1967): Biochemistry of the avian embryo. Macmillan, New York.

Saki. A. A.; Abbasinezhad, M. and Rafati, A. A. (2014). Iron Nanoparticles and Methionine Hydroxy Analogue Chelate in ovo Feeding of Broiler chickens. Int. J. Nanosci. Nanotechnol.,10, 187-196.

SAS' (1996).Operating revenue amounted to MSEK 33,480 $(33,819)$,

Sato, K.; K. Takahash; M. Tohno; Y. Miura; T. Kamada; S. Ikegami and H. Kitazawa (2004). Immuno modulation in gut-associated lymphoid tissue of neonatal chicks by immunobiotic diets. Poult.Sci., 88: $2532-2538$

Scott, N. R. and Chen, H. (2008). National planning. Workshop, www. nseafs. Cornell. edu.

Seo, S.H., H.K. Lee, W.S. Lee, K.S. Shin and I.K. Paik (2008):The Effect of Level and Period of Femethionine Chelate Supplementation on the Iron Content of Boiler Meat Asian-Austr J Anim Sci., Vol. 21, No.10, pp.1501-1505.

Sławińska, A.; M. Siwek; J. Żylińska; J. Bardowski; J. Brzezińska; K.A. Gulewicz; M. and M. Bednarczyk (2014). Influence of synbiotics delivered in ovo on immune organs development and structure. Folia biologica., 62(3): 277-285.

Sturkie, P. D. [ed.]. (1986). Avian physiology. 3rd ed. Springer-Verlag. New York.

Suttle, N. F. (2010). Mineral Nutrition of Livestock, 4thEdition. Oxford, UK: CAB International. 334362.

Toyooka T, Amano T, Suzuki H, and Ibuki Y (2009). DNA can sediment Tio2 particles and decrease the uptake potential by mammalian cells. Science of the Total Environment. 407 (7):2143-50.

Warner, J. D., P.R. Ferket, V. L. Christensen and J. V. Felts (2006). Effect of season, hatch time, and posthatch holding on glycogen status of turkey poults. Poult Sci., Vol. 85, (Suppl.1), (2006), 117 (Abstr.)

Whitnall, M., and D.R. Richardson, (2006): Iron: A new target for pharmacological intervention in neurodegenerative diseases. Seminars Pediatric Neurol. 13, 186-197.

Yair, r., z. and Uni, (2011): Content and uptake of minerals in the yolk of broiler embryos during incubation and effect of nutrient enrichment. Poultry Science 90, 1523-1531.

Zhai, W., and Rowe, D. E. and Peebles, E. D. (2015). Effects of commercial in ovo injection of carbohydrates on broiler embryogenesis. Poultry Science, 90 :1295-1301.
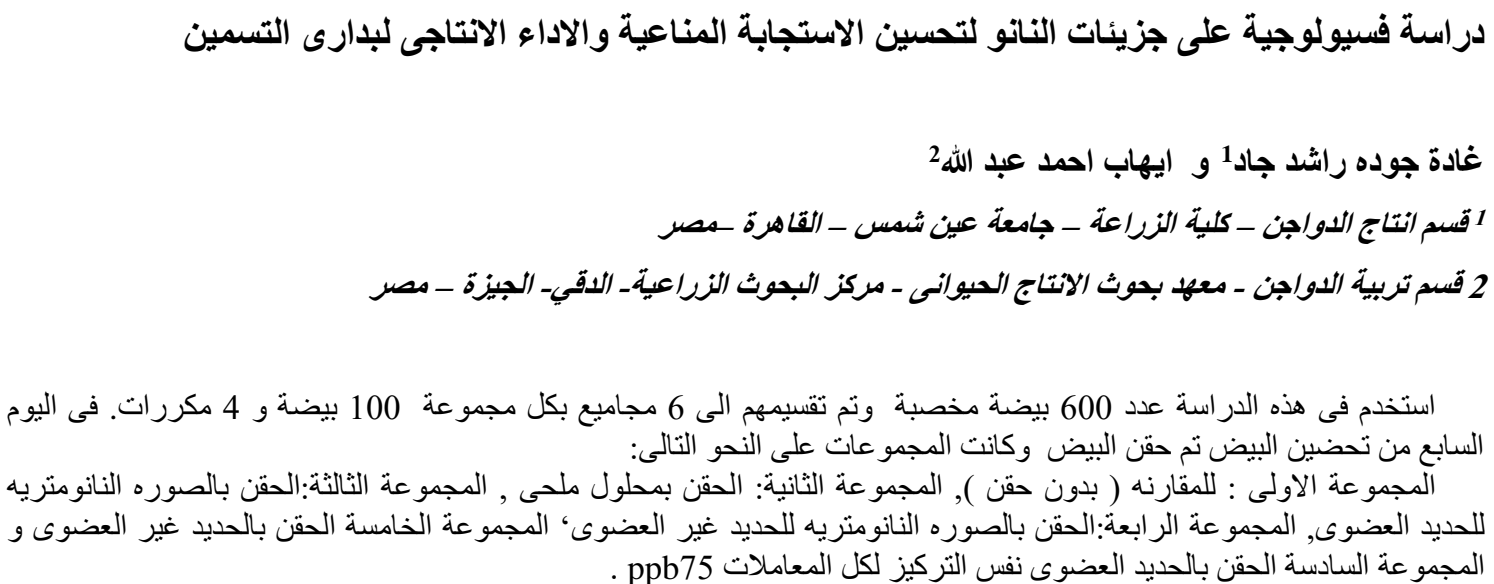


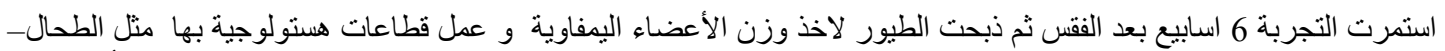

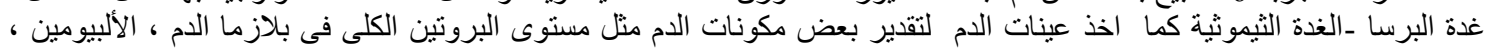

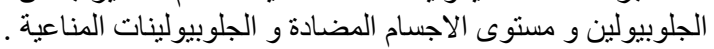

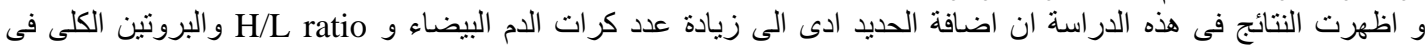

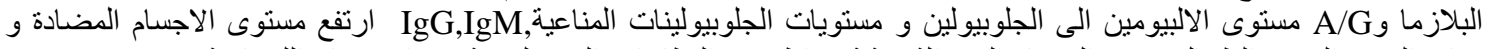

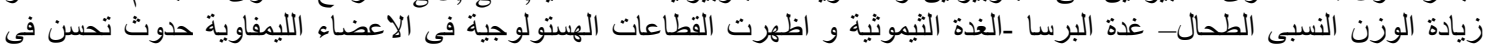

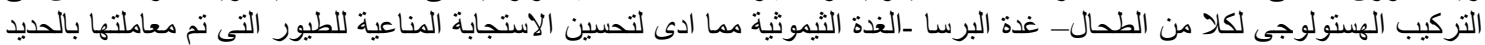

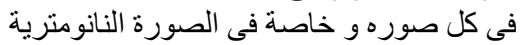

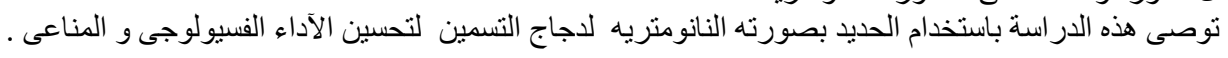

